\title{
Albumin to Globulin Ratio Measurement
}

National Cancer Institute

\section{Source}

National Cancer Institute. Albumin to Globulin Ratio Measurement. NCI Thesaurus. Code C74894.

The determination of the ratio of albumin compared to globulin in a blood sample. The measurement may be expressed as a ratio or percentage. 